\title{
Successful Treatment with Topical Diphenylcyclopropenone for Three Cases of Anogenital Warts in Children
}

\author{
Kazunori Miyata Usho Go Masaru Fujita Tsuyoshi Mitsuishi \\ Department of Dermatology, Tokyo Women's Medical University Yachiyo Medical Center, \\ Yachiyo, Japan
}

\section{Keywords}

Anogenital warts · Human papillomavirus type $6 \cdot$ Diphenylcyclopropenone $\cdot$ Children

\begin{abstract}
Anogenital warts are caused by human papillomavirus types 6 and 11. They are rare in children, and treatment is difficult since conventional treatments are generally painful and require the patient to be anesthetized. Topical diphenylcyclopropenone (DPCP) is a contact immunotherapy used for treatments of recalcitrant warts and alopecia areata. We herein report 3 cases of anogenital warts in children successfully treated with topical DPCP. Our results suggest that topical DPCP may be a valuable option for the treatment of anogenital warts in children who have difficulty with painful destructive therapy.

(C) 2019 The Author(s)

Published by S. Karger AG, Basel
\end{abstract}

\section{Introduction}

Anogenital warts are generally a sexually transmitted disease, therefore they usually appear in adults. They present as soft, skin-colored, cauliflower-like growths. The diagnosis is based primarily on the clinical appearance. Biopsy and histological examination should be 
conducted in case of doubt [1]. Human papillomavirus (HPV) types 6 and 11 are well known to be the cause of anogenital warts. There are several treatment options available for anogenital warts in adults. Anogenital warts sometimes behave recalcitrant to liquid nitrogen cryotherapy. In contrast, the treatment of anogenital warts in children has not yet been well established [2]. Topical immunotherapy has been used for treatment of many diseases since the 1970s. Diphenylcyclopropenone (DPCP) is one of the immunotherapeutic agents, and topical DPCP is known as a safe, effective treatment for recalcitrant warts [3]. However, there are no reports on large series of DPCP used for anogenital warts in children. We herein report 3 cases of anogenital warts in children that were successfully treated with topical DPCP.

\section{Case Reports}

Three children with perianal warts were referred to our hospital (Fig. 1a-c; Table 1). The patients were 2-4 years old, and time from disease onset to presentation ranged from 2 to 4 months. Patients 1 and 2 had been previously treated with cryotherapy for 3-4 months, while patient 3 had been treated with topical application of $5 \%$ imiquimod cream for 2 months, but all were unsuccessful. All lesions were gradually increasing in size during and after the previous treatments. Skin biopsy of one lesion was performed on patient 1, and histopathology showed acanthosis and koilocytosis in the epidermis (Fig. 2). The clinical picture and histology led to the diagnosis of anogenital warts. The lesion also underwent polymerase chain reaction analysis using SK primers as described previously [4]. The analysis of direct sequencing for polymerase chain reaction product indicated HPV type 6 in case 1. Informed consent about topical DPCP was obtained from the patients' parents. To sensitize the patient, $0.1 \%$ DPCP was applied to the left medial arm skin within a 1-cm Patch Tester TM (Torii Pharmaceutical Co., Ltd, Japan) for $24 \mathrm{~h}$. Subsequently, two patients were treated with topical $0.05 \%$ DPCP, while others were treated with $0.5 \%$ DPCP, all applied at home twice per week. After 6 months, all lesions had regressed completely (Fig. 3a-c). Only one adverse effect was recorded. Moderate erythema on the perilesional skin was identified in cases 1 and 3. No systemic adverse effects were noticed. Follow-up 12 weeks later showed no evidence of recurrence.

\section{Discussion}

Anogenital warts in children have been reported to be associated with both mucosal and cutaneous types of HPV [5]. When anogenital warts in children are found, sexual abuse must be ruled out because it is an important mode of transmission. Since there are other modes of transmission, including vertical transmission and extragenital contact, these must also be investigated [6]. The fathers of all patients had sexual contact with commercial sex workers and had genital warts. HPV may have been transmitted to the children accidentally, while they were sitting on their father's lower legs in the bathtub. This behavior suggested that the patients' fathers did not intentionally transmit HPV to the children.

Many treatment options have been evaluated in adults, but the treatment of anogenital warts in children is difficult [7]. Conventional treatment options include chemically destructive measures and physical destruction methods. Chemically destructive measures include 
topical application of podophyllin, 5-fluorouracil, bi-/trichloroacetic acid, and podophyllotoxin. Physical destruction methods include cryotherapy, laser vaporization, electrocautery, and surgical excision [2, 8-10]. Many of these treatments are painful and require multiple visits to the clinic or operating room [7]. Topical DPCP is a type of contact immunotherapy mainly used in the treatment of alopecia areata recalcitrant viral warts [11]. According to previous reports, the cure rates of DPCP immunotherapy for viral warts ranged from 45 to $88 \%$ [12]. The mechanism of the action of immunotherapy for viral warts has been less thoroughly investigated. It is known that topical immunotherapy involves the generation of a delayed-type hypersensitivity reaction. DPCP forms hapten with wart proteins. This DPCP hapten is recognized by T cells, eventually resulting in the wart's destruction $[12,13]$. Our patients were previously treated with cryotherapy or topical application of $5 \%$ imiquimod cream, but without any result. Therefore, we chose topical DPCP as the treatment, and the results were very effective. This indicated that topical DPCP may be a valuable option for the treatment of anogenital warts in children.

\section{Conclusion}

The successful progress in our cases suggested that topical DPCP might be an effective and preferred treatment option for anogenital warts in children. For children, pain should be considered an important factor in the choice of treatment. The advantage of topical DPCP is in the convenience of home treatment and the absence of pain. We suggest that topical DPCP is an effective and preferred treatment option for anogenital warts in children and should be considered as an alternative to aggressive and painful therapies.

\section{Statement of Ethics}

The authors have no ethical conflicts to disclose.

\section{Disclosure Statement}

The authors have no conflicts of interests to declare.

\section{References}

1 Percinoto AC, Danelon M, Crivelini MM, Cunha RF, Percinoto C. Condyloma acuminata in the tongue and palate of a sexually abused child: a case report. BMC Res Notes. 2014 Jul;7(1):467.

2 Lacey CJ, Woodhall SC, Wikstrom A, Ross J. 2012 European guideline for the management of anogenital warts. J Eur Acad Dermatol Venereol. 2013 Mar;27(3):e263-70.

3 Choi Y, Kim DH, Jin SY, Lee AY, Lee SH. Topical immunotherapy with diphenylcyclopropenone is effective and preferred in the treatment of periungual warts. Ann Dermatol. 2013 Nov;25(4):434-9.

4 Sasagawa T, Mitsuishi T. Novel polymerase chain reaction method for detecting cutaneous human papillomavirus DNA. J Med Virol. 2012 Jan;84(1):138-44. 


\section{Case Reports in Dermatology}

5 Sikanić Dugić N, Ljubojević Hadžavdić S, Pustišek N, Hiršl Hećej V. Treatment of anogenital warts in an 18month-old girl with 5\% imiquimod cream. Acta Dermatovenerol Croat. 2014;22(1):40-3.

6 Leclair E, Black A, Fleming N. Imiquimod 5\% cream treatment for rapidly progressive genital condyloma in a 3-year-old girl. J Pediatr Adolesc Gynecol. 2012 Dec;25(6):e119-21.

7 Chang GJ, Welton ML. Human papillomavirus, condylomata acuminata, and anal neoplasia. Clin Colon Rectal Surg. 2004 Nov;17(4):221-30.

8 Moresi JM, Herbert CR, Cohen BA. Treatment of anogenital warts in children with topical $0.05 \%$ podofilox gel and 5\% imiquimod cream. Pediatr Dermatol. 2001 Sep-0ct;18(5):448-50.

9 Silverberg NB. Human papillomavirus infections in children. Curr Opin Pediatr. 2004 Aug;16(4):402-9.

10 Uzuncakmak TK, Koska MC, Karadağ AS, Akdeniz N. A Case Report of Verruca Vulgaris on basis of Alopecia Areata Successfully Treated with Diphenylcyclopropenone. Int J Trichology. 2017 Jan-Mar;9(1):35-7.

11 Suh DW, Lew BL, Sim WY. Investigations of the efficacy of diphenylcyclopropenone immunotherapy for the treatment of warts. Int J Dermatol. 2014 Dec;53(12):e567-71.

12 Venkatesh K, Yun J, Bakis-Petsoglou S. Anaphylaxis to diphenylcyclopropenone during sensitization for wart treatment - a case report. JAAD Case Rep. 2018 Oct;4(9):872-3.

13 Varma S, Lathrop E, Haddad LB. Pediatric condyloma acuminata. J Pediatr Adolesc Gynecol. 2013 Dec;26(6):e121-2.
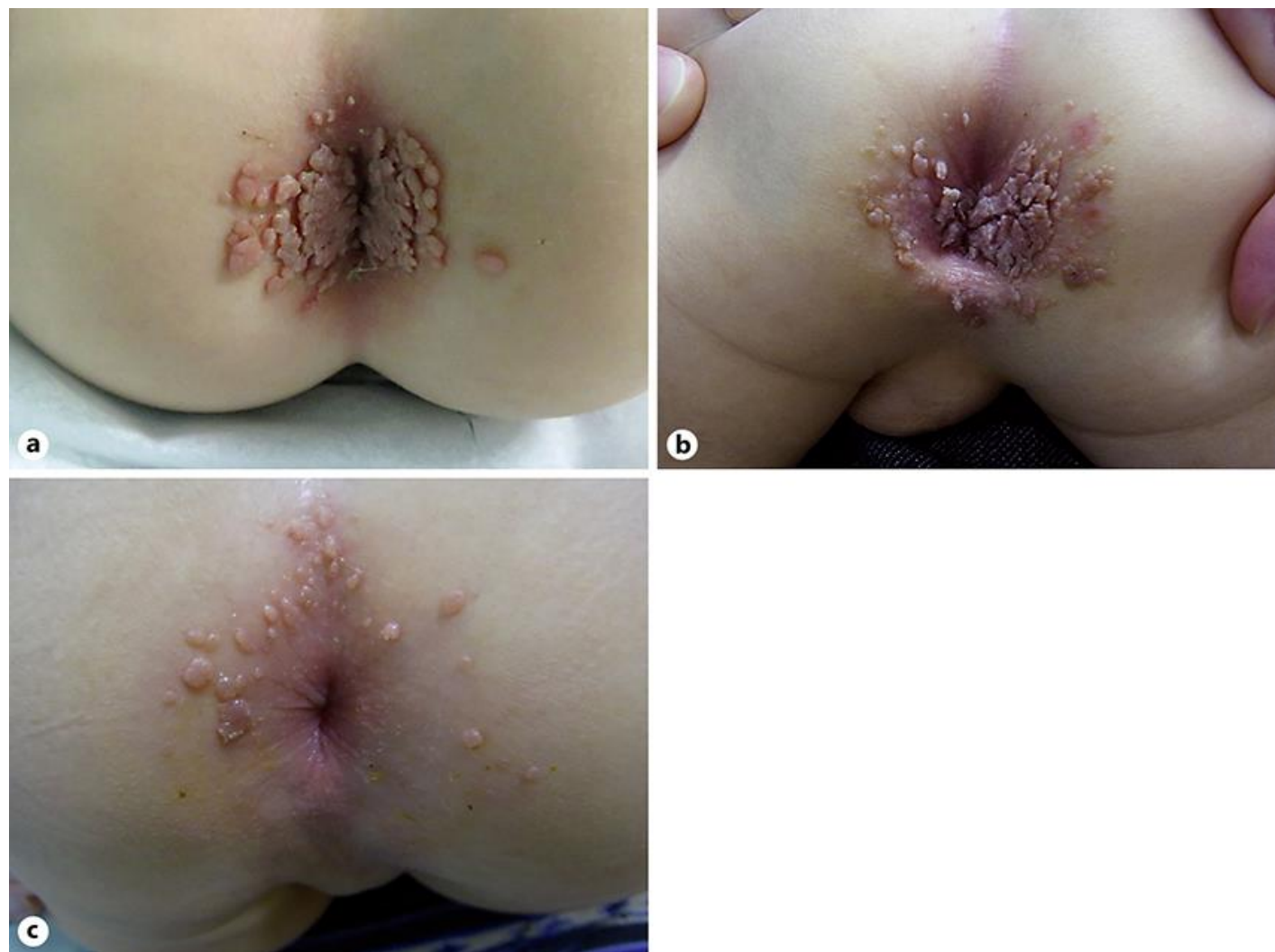

Fig. 1. Clinical appearance of anogenital warts prior to treatment in cases 1 (a), 2 (b), and 3 (c). 


\section{Case Reports in Dermatology}

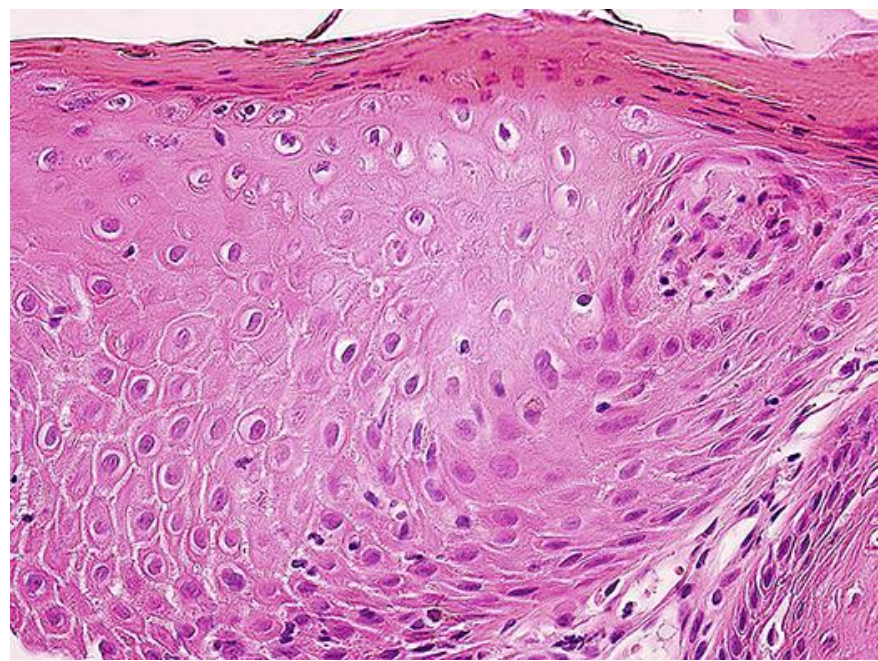

Fig. 2. Histopathological findings of anogenital warts in case 1. Moderate acanthosis and koilocytotic cells with irregular nuclei in the epidermis (hematoxylin and eosin staining, $\times 400$ ). 


\section{Case Reports in Dermatology}

Case Rep Dermatol 2019;11:123-129

(C) 2019 The Author(s). Published by S. Karger AG, Basel www.karger.com/cde

Miyata et al.: Topical Diphenylcyclopropenone for Anogenital Warts in Children
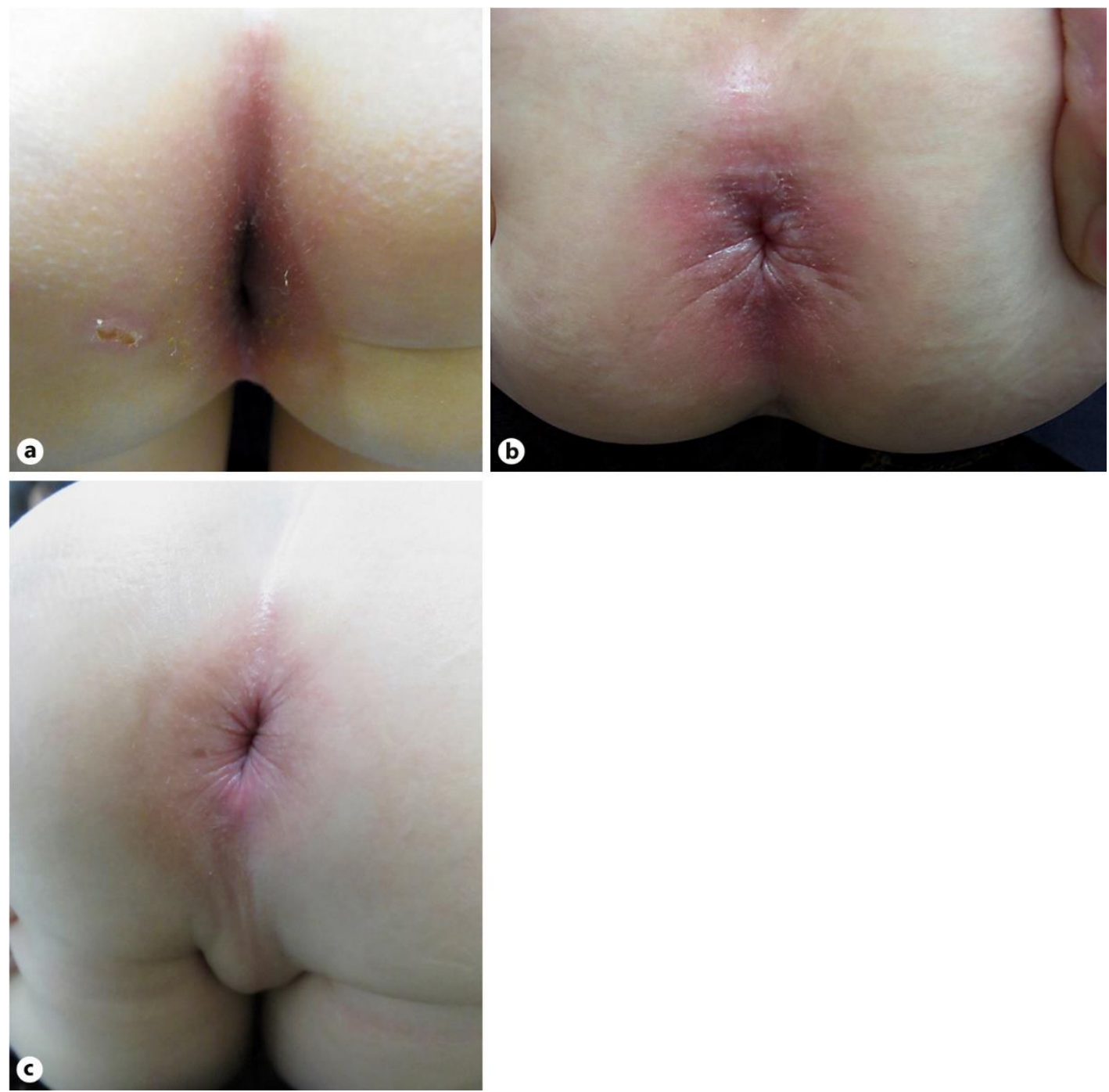

Fig. 3. Complete regression of the lesions after 6 months of diphenylcyclopropenone treatment in cases 1 (a), 2 (b), and 3 (c) 
Table 1. Clinical characteristics and treatment of the patients

\begin{tabular}{llllllll}
\hline $\begin{array}{l}\text { Case } \\
\text { No. }\end{array}$ & $\begin{array}{l}\text { Age, } \\
\text { years }\end{array}$ & Sex & $\begin{array}{l}\text { Onset, } \\
\text { months }\end{array}$ & $\begin{array}{l}\text { Penile } \\
\text { warts on } \\
\text { father }\end{array}$ & $\begin{array}{l}\text { Previous } \\
\text { treatment }\end{array}$ & $\begin{array}{l}\text { Treatment } \\
\text { months }\end{array}$ & $\begin{array}{l}\text { Time of } \\
\text { resolution, } \\
\text { months }\end{array}$ \\
\hline 1 & 4 & male & 4 & yes & cryotherapy & $0.05 \%$ DPCP & 6 \\
2 & 2 & male & 4 & yes & $\begin{array}{l}\text { cryotherapy } \\
5 \% \text { imiquimod cream }\end{array}$ & $0.05 \%$ DPCP & 6 \\
3 & 2 & male & 2 & yes & DPCP & 6 \\
\hline
\end{tabular}

DPCP, diphenylcyclopropenone. 